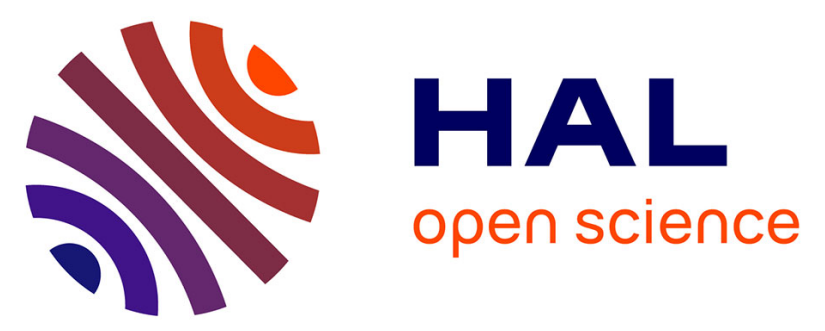

\title{
Estimation of joint contact pressure in the index finger using a hybrid finite element musculoskeletal approach
}

Barthélémy Faudot, Jean-Louis Milan, Benjamin Goislard de Monsabert, Thomas Le Corroller, Laurent Vigouroux

\section{- To cite this version:}

Barthélémy Faudot, Jean-Louis Milan, Benjamin Goislard de Monsabert, Thomas Le Corroller, Laurent Vigouroux. Estimation of joint contact pressure in the index finger using a hybrid finite element musculoskeletal approach. Computer Methods in Biomechanics and Biomedical Engineering, 2020, pp.1-11. 10.1080/10255842.2020.1793965 . hal-02905574

\section{HAL Id: hal-02905574 \\ https://hal-amu.archives-ouvertes.fr/hal-02905574}

Submitted on 4 May 2021

HAL is a multi-disciplinary open access archive for the deposit and dissemination of scientific research documents, whether they are published or not. The documents may come from teaching and research institutions in France or abroad, or from public or private research centers.
L'archive ouverte pluridisciplinaire HAL, est destinée au dépôt et à la diffusion de documents scientifiques de niveau recherche, publiés ou non, émanant des établissements d'enseignement et de recherche français ou étrangers, des laboratoires publics ou privés. 


\section{Estimation of joint contact pressure in the index finger using a hybrid finite element musculoskeletal approach}

Barthélémy Faudot, Jean-Louis Milan , Benjamin Goislard de Monsabert, Thomas Le Corroller \& Laurent Vigouroux 


\title{
Estimation of joint contact pressure in the index finger using a hybrid finite element musculoskeletal approach
}

\author{
Barthélémy Faudot $^{\mathrm{a}, \mathrm{b}} \mathbb{D}$, Jean-Louis Milan ${ }^{\mathrm{a}, \mathrm{b}}$, Benjamin Goislard de Monsabert ${ }^{\mathrm{a}}$, Thomas Le Corroller ${ }^{\mathrm{a}, \mathrm{c}}$ \\ and Laurent Vigouroux ${ }^{\mathrm{a}}$ \\ ${ }^{a}$ Aix Marseille University, CNRS, ISM, Marseille, France; ${ }^{b}$ APHM, Institute for Locomotion, Department of Orthopaedics and \\ Traumatology, St Marguerite Hospital, Marseille, France; 'APHM, Institute for Locomotion, Department of Radiology, St Marguerite \\ Hospital, Marseille, France
}

\begin{abstract}
The knowledge of local stress distribution in hand joints is crucial to understand injuries and osteoarthritis occurrence. However, determining cartilage contact stresses remains a challenge, requiring numerical models including both accurate anatomical components and realistic tendon force actuation. Contact forces in finger joints have frequently been calculated but little data is available on joint contact pressures. This study aimed to develop and assess a hybrid biomechanical model of the index finger to estimate in-vivo joint contact pressure during a static maximal strength pinch grip task. A finite element model including bones, cartilage, tendons, and ligaments was developed, with tendon force transmission based on a tendon-pulley system. This model was driven by realistic tendon forces estimated from a musculoskeletal model and motion capture data for six subjects. The hybrid model outputs agreed well with the experimental measurement of fingertip forces and literature data on the physiological distribution of tendon forces through the index finger. Mean contact pressures were $6.9 \pm 2.7 \mathrm{MPa}$, $6.2 \pm 1.0 \mathrm{MPa}$ and $7.2 \pm 1.3 \mathrm{MPa}$ for distal, proximal interphalangeal and metacarpophalangeal joints, respectively. Two subjects had higher mean contact pressure in the distal joint than in the other two joints, suggesting a mechanical cause for the prevalence of osteoarthritis in the index distal joint. The inter-subject variability in joint contact pressure could be explained by different neuromuscular strategies employed for the task. This first application of an effective hybrid model to the index finger is promising for estimating hand joint stresses under daily grip tasks and simulating surgical procedures.
\end{abstract}

\section{KEYWORDS}

Hand biomechanics; joint contact pressure; pinch grip task; finite element analysis; musculoskeletal model

\section{Introduction}

The human hand is a sophisticated biological tool involved in numerous everyday activities (Bardo et al. 2018). The gripping tasks performed by the hand are essential for most movements in daily and working life. The pinch grip, which consists in holding objects between the thumb and the index fingertips (Vergara et al. 2014), is one of the commonest among the various techniques (e.g. cylindrical, key pinch, hook grip) (Napier 1956). Because of its specific biomechanical configuration, this grip technique can lead to high joint loadings that expose the fingers to injuries such as rheumatoid arthritis and osteoarthritis (OA) (Jensen et al. 1999; McQuillan et al. 2016). Cumulative excessive stress acting on normal joints has indeed been identified as one of the main risk factors for the development of OA (Guilak 2011; Buckwalter et al. 2013). Hence, quantifying the biomechanical stress distribution on the finger's musculoskeletal system, especially joint contact pressure, could provide a better understanding of joint diseases (Goislard de Monsabert et al. 2014) and improve rehabilitation (Fowler and Nicol 2000; Completo et al. 2018).

Direct measurements of joint pressures have been estimated in-vivo using pressure sensors (Rikli et al. 2007) and instrumented prostheses for large joints (D'Lima et al. 2006). However, the highly invasive nature of such techniques makes them ethically questionable and technically challenging, especially when applied to the small finger joints. Only a few in-vitro experimental data for the hand are available, due to the joint size and to the surrounding tissues that complicate the insertion of such sensors. Therefore, computational modelling, being non-invasive, appears 
to be the most suitable method for estimating joint mechanics.

Finite element (FE) and musculoskeletal (MSK), also known as multi-rigid body, are the main modelling approaches currently used to study joint loadings (Henak et al. 2013). They have been widely applied to the lower limb during isometric tasks (Cheung et al. 2005) and gait locomotion (Andriacchi et al. 2009) to estimate whether joint kinematics, reaction forces or joint cartilage stress. Due to the number of anatomical components involved and the complexity of softtissue interaction, multi-articular systems such as the finger, wrist or ankle have received less attention. Most hand biomechanical models use an MSK representation for either the index finger (Fowler and Nicol 2000; Synek and Pahr 2016), the thumb-index pinch complex (Barry et al. 2018) or the entire hand (Goislard de Monsabert et al. 2014). Although such models provide estimations of tendon forces and resultant joint contact forces, they neglect the nonlinear deformation of soft tissues and the local stress distribution. Conversely, FE finger models provide estimations of local contact mechanics but focus on a single joint (Hashizume et al. 1994), model joints in $2 \mathrm{D}$ (Butz et al. 2012a), neglect muscle actions and tendon paths (Butz et al. 2012b) and apply nonphysiological boundary conditions (Harih 2019). To take advantage of both approaches, hybrid MSK-FE models have been developed to investigate different musculoskeletal structures, such as the wrist (Gíslason et al. 2010), the foot (Isvilanonda et al. 2012) or the knee (Besier et al. 2005; Halonen et al. 2017). However, the implementation of this hybrid approach remains challenging when modelling the hand. Multijoint configuration makes it particularly difficult to assess and validate the numerical procedure, and a few studies have studied the mechanical properties of finger tissues, focusing mainly on tendon and pulley strength (Lin et al. 1989; Garcia-Elias et al. 1991) and cartilage stiffness (Dourthe et al. 2019).

A hybrid MSK-FE model representing bones, cartilage, tendons, annular pulleys, and ligaments while considering the multi-joint actions of tendons would help to improve the understanding of musculoskeletal diseases. To the best of our knowledge, no studies have so far applied this hybrid approach to the hand joints. The pinch grip position was chosen as studycase because it is one of the most frequently used and a critical task for osteoarthritis occurrence and development (Napier 1956; Moran et al. 1985; Jensen et al. 1999). Thus, the purpose of this paper was to provide an assessed hybrid biomechanical model of the index finger that estimates the in-vivo joint contact pressure by applying realistic muscle actions during a static maximal strength pinch grip task. The model was evaluated through a sensitivity analysis on cartilage parameters and input muscle force. It was then used to compare mechanical loadings in the three finger joints of six healthy participants.

\section{Methods}

The workflow of the study is presented in Figure 1.

\section{Experimental kinematic and force data}

The experimental setup and protocol already reported (Goislard de Monsabert et al. 2014) are briefly described here. Ten healthy right-handed males free of upper extremity disorders were recruited (age: $25.5 \pm 3.2$ years; height: $178.6 \pm 6.1 \mathrm{~cm}$; weight: $71.2 \pm 7.2 \mathrm{~kg}$; hand length: $19.0 \pm 0.8 \mathrm{~cm})$. Kinematic and force data (Figure 2) were simultaneously recorded. A six-axial force sensor (Nano-25; ATI Industrial Automation, USA) $5.5 \mathrm{~cm}$ long was used to record the force applied by the thumb and index fingertips. The 3D position of hand segments was tracked using spherical reflecting markers and a sixcamera optoelectronic system (MX T40; Vicon, UK). Joint angles and the three grip force components were then inputted into the MSK model.

\section{Tendon force estimation using a musculoskeletal model}

The MSK model used in this paper was first published in (Vigouroux et al. 2006), then developed and used in several studies published over the last decade, the full description of the MSK model is provided in (Goislard de Monsabert et al. 2012). The model estimated 42 tendon forces to balance 23 degrees of freedom (DoF) representing the five fingers and the wrist. The segments were modelled as rigid bodies articulated by sixteen frictionless joints. First, an inverse dynamics process was performed and then the 42 tendon forces required to balance external forces were estimated using a static optimization to solve the muscular redundancy problem. In the second step, joint reaction forces were derived from tendon and external fingertip forces using the force equilibrium equation. 


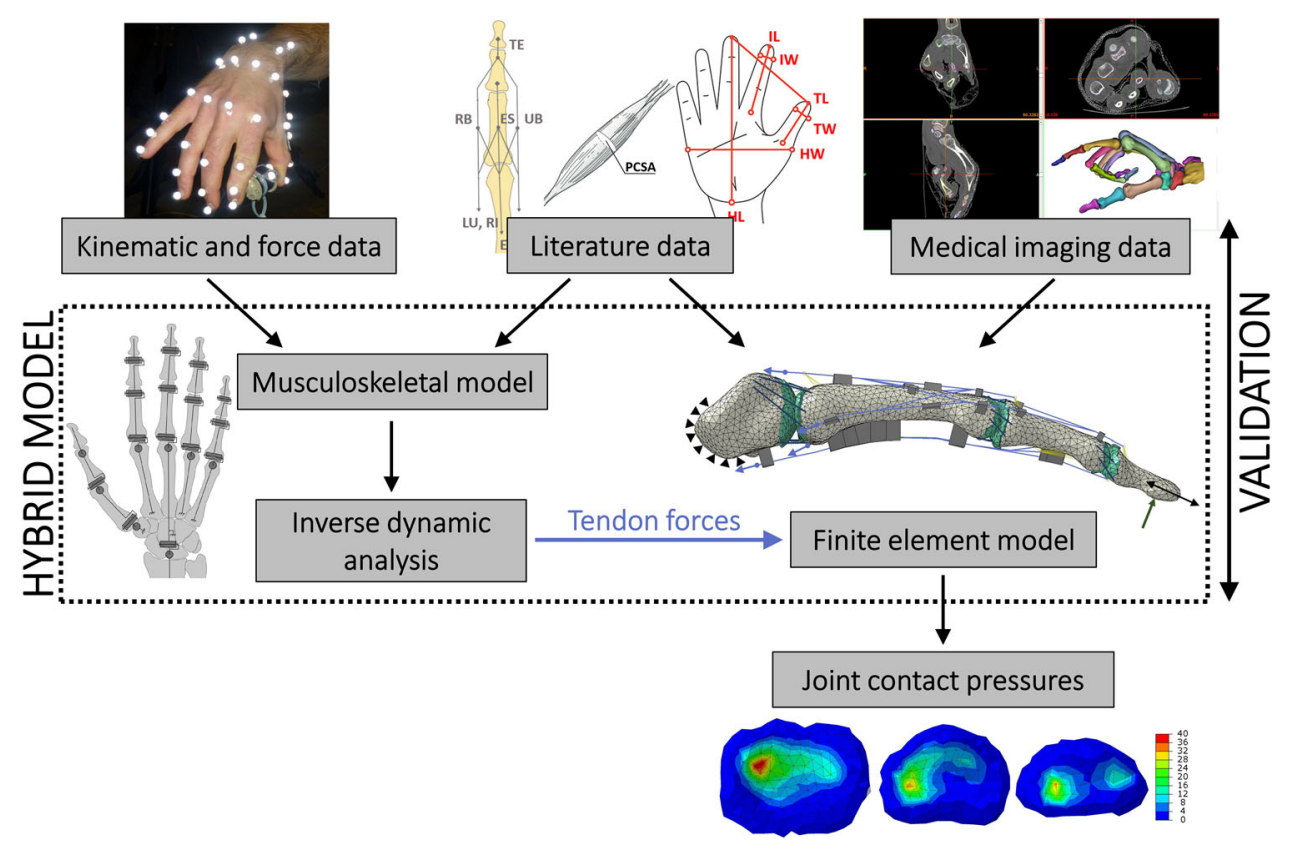

Figure 1. Hybrid musculoskeletal-finite element model applied to the index finger for the estimation of joint contact pressure during a static maximal strength pinch grip task. The musculoskeletal model applied to six subjects estimated tendon and joint forces from motion capture and force data through an inverse dynamic approach. The finite element model based on medical imaging data and including all the major structures of the index finger was driven by tendon forces of the musculoskeletal model. This hybrid approach assessed by comparison with experimental data and musculoskeletal results yielded mean and maximal contact pressures at the three index finger joints.

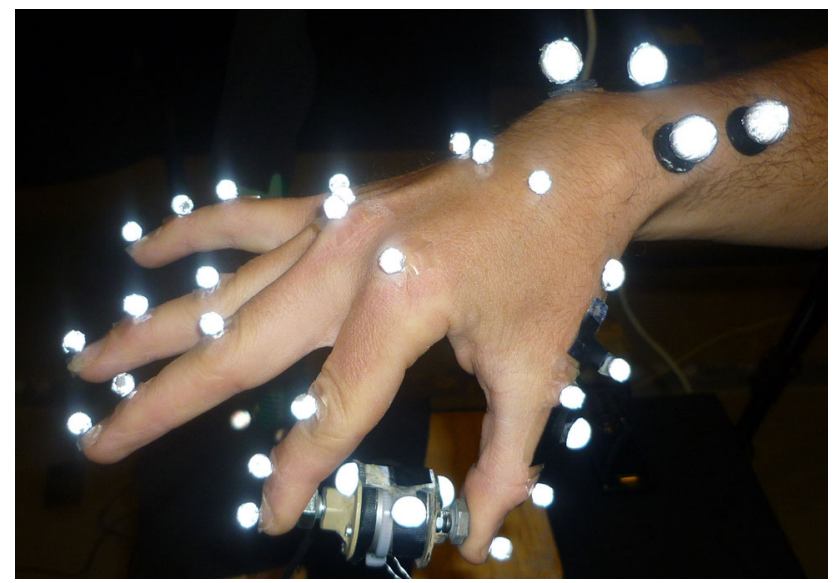

Figure 2. Pulp pinch grip posture and experimental acquisition system. A motion capture system with spherical markers on bony landmarks and an axial force sensor between the thumb and index fingertips were used.

\section{Development of the finite element environment}

\section{Modelling bone and cartilage geometry}

A healthy male subject free of upper extremity disorders was recruited to acquire computed tomography (CT) images of the right hand (age: 37 years; height: $185 \mathrm{~cm}$; weight: $74 \mathrm{~kg}$; hand length: $19.7 \mathrm{~cm}$ ). The participant signed an informed consent form and the protocol was approved by the local ethics committee.
The CT system was a LightSpeed VCT (GE Medical Systems, USA) $(150 \mathrm{~mA} \times 120 \mathrm{kV}$; slice thickness $625 \mu \mathrm{m}$; pixel size $325 \mu \mathrm{m}$ ). The subject placed his hand in a semi-rigid cast that constrained him in a pinch grip posture. The cast was made before the acquisition to avoid any effect of fatigue. Polyurethane resin tapes (Soft Cast, $3 \mathrm{M}$, USA) were positioned while the subject was holding a $5.5 \mathrm{~cm}$ long tube, i.e. the same length as the force sensor.

Segmentation of bones was performed from the CT-scan acquisition using the $3 \mathrm{D}$ image reconstruction software Mimics (Research 20.0; Materialise, Belgium). Index phalanges and truncated metacarpal bone were meshed using quadratic tetrahedral elements (C3D10) with a maximum element edge length of $1.5 \mathrm{~mm}$ determined after a mesh convergence analysis. Solid geometries were imported into Abaqus (2018; Simulia, USA). The cartilage was manually created by identifying joint surfaces on bones and then extruding surface elements to form two-layer wedge elements (C3D6), each of whose widths equalled half the minimum distance between bones (Anderson et al. 2010). The thickness of each cartilage layer at DIP, PIP and MCP joints was of $0.45 \mathrm{~mm}, 0.55 \mathrm{~mm}$ and $0.85 \mathrm{~mm}$, respectively. The FE model's total number of elements was roughly 200000 . 


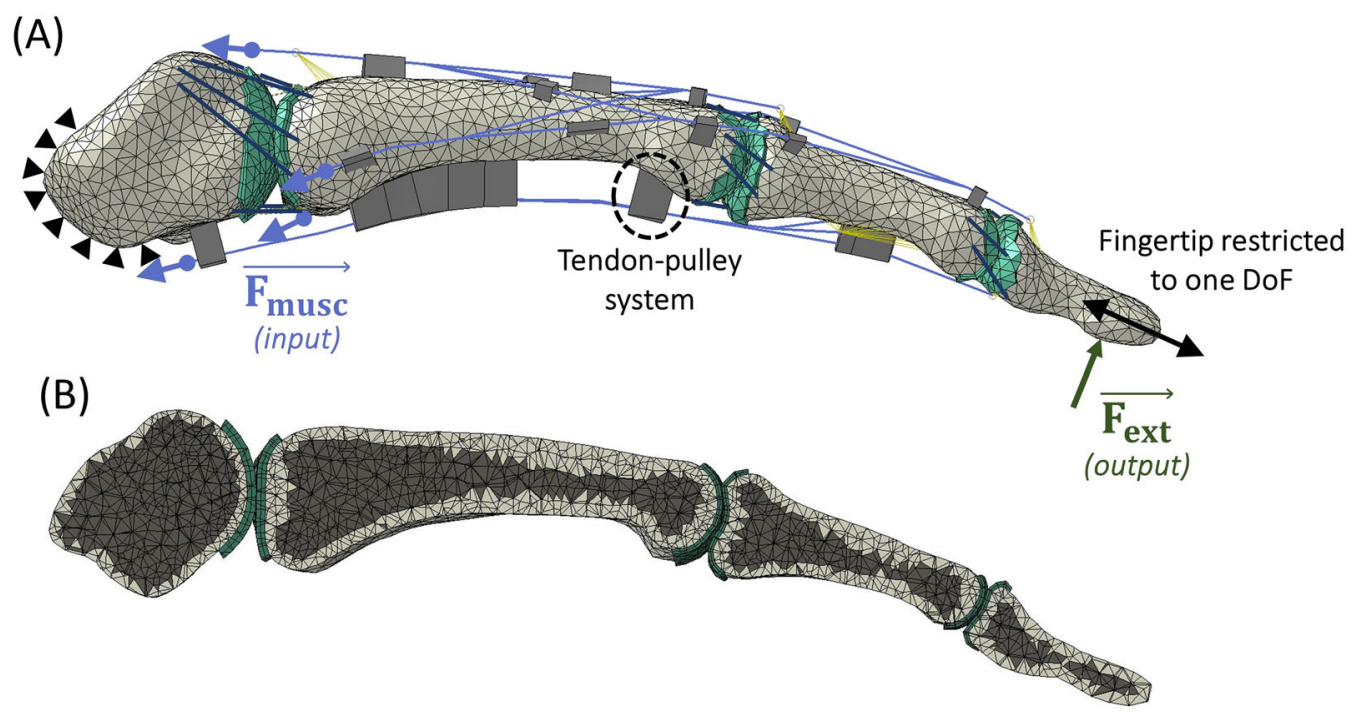

Figure 3. (A) Index finger finite element model of the hybrid approach including bones, cartilage, tendons, annular pulleys, and ligaments. Cartilage in green was obtained by extrusion of the bone surfaces with wedge elements. Tendons and annular pulleys in light blue and grey were modelled with beam and shell elements, respectively. Ligaments in dark blue were represented by multiple non-linear spring elements. The truncated metacarpal bone was fully constrained and the fingertip restricted to one degree of freedom (DoF) resulting in an external fingertip reaction force $\left(\mathrm{F}_{\text {ext }}\right)$. Datasets of tendon forces $\left(\mathrm{F}_{\text {musc }}\right)$ were applied along the last segment of each tendon. (B) Material properties distribution between cortical (in light grey) and cancellous bone (in black) on a section of the index finger bones.

\section{Modelling multi-articular tendons and pulleys}

All the tendons and muscles involved in index finger function were modelled: terminal extensor, flexor digitorum profundus (FDP) at distal interphalangeal (DIP) joint, extensor slip, radial band, ulnar band, flexor digitorum superficialis (FDS) at proximal interphalangeal (PIP) joint and long extensor (LE) (considering both extensor digitorum communis (EDC) and extensor digitorum indicis (EDI)), radial interosseus (RI), ulnar interosseus (UI), lumbrical (LU) at metacarpophalangeal (MCP) joint. Tendon paths were based on the same geometrical dataset (An et al. 1979) as the MSK model and scaled according to phalanx dimensions of the scanned subject. Each tendon was modelled using straight beams (B31) to connect the points given by the anatomical dataset, i.e. two points at each joint. The complex assembly of multi-directional fibres of the extensor hood mechanism was represented using a discrete rhomboidal network of strings as proposed by (Zancolli 1979). Multi-articular flexor tendons were held tight to the bone by annular pulleys and several small sheaths were modelled to hold the tendons of the extensor mechanism in the adequate position (see Figure 3(A)). Pulleys and sheaths were modelled with shell elements (S4) providing via-points for tendons and indirectly modelling the wrapping phenomena of tendons onto finger bones.

\section{Modelling tissue properties}

Finger bones were modelled as a linear elastic isotropic material, distinguishing between cortical $(\mathrm{E}=18 \mathrm{GPa}, \quad v=0.2)$ and cancellous bone $(E=300 \mathrm{MPa}, v=0.25)$, see Figure 3(B). Cartilage was modelled using a Neo-Hookean hyper-elastic material detailed in Table 1. Neo-Hookean constants $\left(\mathrm{C}_{10}\right.$ and $\left.\mathrm{D}_{1}\right)$ were calculated, as in Equation (1), using a Young's modulus of $1.64 \mathrm{MPa}$ (Dourthe et al. 2019) and a Poisson's ratio of 0.2. Supplementary analysis was performed to investigate the effect of cartilage material properties on the model results.

$$
C_{10}=\frac{E}{4(1+v)} \text { and } D_{1}=\frac{6(1-2 v)}{E}
$$

Collateral ligaments and volar plates were modelled as the main stabilizers of the index finger joints (Minami et al. 1985). The same attachment points as those used for the MSK model were estimated from an anatomical study (An et al. 1979). Distributed insertions were simulated by applying ligaments in parallel at adjacent node points on the bone surface. Ligaments were modelled as non-linear spring elements (CONN3D2) with tension-only behaviour and pre-strain of $10 \mathrm{~N} / \mathrm{mm}$ playing the role of initial stabilizer (Maas et al. 2016). Model values are summarized in Table 1. 
Table 1 Material properties and element types of the index finger hybrid finite element model.

\begin{tabular}{llll}
\hline Component & \multicolumn{1}{c}{ Element type } & Constitutive model & \multicolumn{1}{c}{ Constants } \\
\hline Cortical bone & Tetrahedral & Linear elastic & $\mathrm{E}=18 \mathrm{GPa} ; v=0.2$ \\
Cancellous bone & Tetrahedral & Linear elastic & $\mathrm{E}=300 \mathrm{MPa} ; v=0.25$ \\
Cartilage & Wedge & Hyper-elastic Neo-Hookean & $\mathrm{C}_{10}=0.34 \mathrm{MPa} ; \mathrm{D}_{1}=2.20 \mathrm{MPa}^{-1}$ \\
Tendons & Tension-only beam & Linear elastic & $\mathrm{E}=3 \mathrm{GPa} ; v=0.3$ \\
Pulleys & Shell & Linear elastic & $\mathrm{E}=1 \mathrm{GPa} ; v=0.3$ \\
Ligaments & Tension-only connector & Non-linear elastic & From $40 \mathrm{~N} / \mathrm{mm}$ to $150 \mathrm{~N} / \mathrm{mm}$ \\
\hline
\end{tabular}

Table 2 Mesh quality metrics of the hybrid finite element model.

\begin{tabular}{lcc}
\hline Mesh quality metric & Assessment criteria & Accurate elements \\
\hline Jacobian elements & $>0.2$ & $94 \%$ \\
Aspect ratio & $<3$ & $96 \%$ \\
Max angles & $<120^{\circ}$ & $99 \%$ \\
\hline
\end{tabular}

\section{Estimation of joint contact pressure using the hybrid model}

\section{Input tendon loads and boundary conditions}

FE simulations were driven by tendon forces provided by the MSK analysis previously described, hence resulting in a hybrid model. Four of the ten subjects were excluded from the analysis due to the large difference between their postures and that of the scanned subject, with an exclusion criterion of $20^{\circ}$ flexion angle at MCP, PIP and DIP joints. For the six remaining subjects, tendon forces were applied to the end of each tendon in the direction of the last beam segment (Figure 3(A)). Supplementary analysis was also conducted to investigate the effect of tendon forces on the model results. Bone and cartilage were fixed together to allow no relative motion between them. A friction coefficient of 0.02 (Wright and Dowson 1976) was applied at each joint surface. The proximal end of the truncated metacarpal bone was fully constrained and index fingertip nodes were restricted to one DoF to model the contact with the force sensor (see Figure 3(A)).

\section{Solver and outputs}

The Abaqus explicit solver was used for the analysis making the contact model robust. The contact pressure at the three index finger joints was then calculated for each subject and compared in terms of maximal and mean values as well as contact areas. Other intermediary outputs (see below) were also extracted to assess the quality of the model.

\section{Verification and assessment of the hybrid model}

Several analyses were performed to assess the quality of the hybrid model. The FE environment was evaluated through an assessment of the mesh quality and a convergence criterion. Resultant fingertip forces estimated in the hybrid model at the fixed fingertip nodes were compared to the experimental forces measured by the force sensor. The ratio of inputted flexor tendon forces to estimated fingertip forces provided by the hybrid model, as well as transmission forces through the extensor mechanism, were compared to literature values. Reaction forces of each joint in the hybrid model were compared with those of the MSK model.

\section{Results}

\section{Results of the MSK model}

The MSK model results are summarized here, for a full description see (Goislard de Monsabert et al. 2014). Tendon forces, sum of all tendon forces, FDP to FDS tendon force ratio and FDP to LE tendon force ratio for each of the six subjects are given in Supplementary Material A. For flexor tendons, resulting tensions were $116.8 \pm 52.7 \mathrm{~N}$ and $112.5 \pm 69.3 \mathrm{~N}$ for the FDP and FDS tendons, respectively. For the extensor mechanism, resulting tensions were $5.7 \pm 5.7 \mathrm{~N}, \quad 159.3 \pm 29.7 \mathrm{~N}, \quad 0.0 \pm 0.0 \mathrm{~N}, \quad 66.1 \pm 17.7 \mathrm{~N}$, $84.9 \pm 22.8 \mathrm{~N}$ for the LU, RI, UI, EDC and EDI tendons, respectively.

A high inter-subject variability in finger postures was observed during the gripping task. DIP, PIP, and MCP flexion angles were $19.0 \pm 8.1^{\circ}, 11.4 \pm 9.3^{\circ}$ and $58.5 \pm 6.5^{\circ}$, respectively. The scanned subject had flexion angles of $9.3^{\circ}, 16.9^{\circ}$, and $47.6^{\circ}$ for DIP, PIP and MCP joints, respectively.

\section{Finite element environment quality indicators}

Mesh quality was checked against the recommendations of (Burkhart et al. 2013), detailed in Table 2, ensuring that elements with poor mesh metrics were located far from areas of interest. The model converged, at the end of the load step, with a mean kinetic energy of $3.4 \%$ of the total strain energy. Any dynamic behaviour was excluded according to (Choi et al. 2002), leading to a quasi-static simulation. 
Table 3 The ratios of inputted FDP tendon to estimated fingertip pinch grip force, FDS tendon to estimated fingertip pinch grip force and proximal slip band to terminal extensor band force of the extensor mechanism were calculated and compared with measurements of the literature.

\begin{tabular}{lccc}
\hline & $\begin{array}{c}\text { FDP to fingertip } \\
\text { force ratio }\end{array}$ & $\begin{array}{c}\text { FDS to fingertip } \\
\text { force ratio }\end{array}$ & $\begin{array}{c}\text { Proximal slip to terminal extensor } \\
\text { force ratio }\end{array}$ \\
\hline Hybrid model & $2.5 \pm 0.9$ & $2.4 \pm 1.2$ & $1.9 \pm 0.3$ \\
Schuind et al. (1992) & $7.9 \pm 6.3$ & $1.7 \pm 1.5$ & - \\
Dennerlein et al. (1998) & - & $3.3 \pm 1.4$ & - \\
Kursa et al. (2005) & $2.4 \pm 0.7$ & $1.5 \pm 1.0$ & - \\
Valero-Cuevas et al. (2007) & - & - & 2.2 \\
\hline
\end{tabular}

Table 4 External fingertip force and joint reaction force at distal interphalangeal (DIP), proximal interphalangeal (PIP) and metacarpophalangeal (MCP) joints from the musculoskeletal model and the hybrid model.

\begin{tabular}{|c|c|c|c|c|}
\hline & $\begin{array}{l}\text { External fingertip } \\
\text { force }(\mathrm{N})\end{array}$ & $\begin{array}{l}\text { DIP joint reaction } \\
\text { force }(\mathrm{N})\end{array}$ & $\begin{array}{l}\text { PIP joint reaction } \\
\text { force }(\mathrm{N})\end{array}$ & $\begin{array}{l}\text { MCP joint reaction } \\
\text { force }(\mathrm{N})\end{array}$ \\
\hline $\begin{array}{l}\text { MSK model } \\
\text { Hybrid model }\end{array}$ & $\begin{array}{l}61.1 \pm 12.1 \\
46.7 \pm 10.3\end{array}$ & $\begin{array}{l}145.5 \pm 111.4 \\
255.5 \pm 111.3\end{array}$ & $\begin{array}{c}266.7 \pm 92.7 \\
394.7 \pm 111.8\end{array}$ & $\begin{array}{c}515.0 \pm 92.3 \\
585.9 \pm 119.8\end{array}$ \\
\hline
\end{tabular}

\section{Assessment of the hybrid model}

The hybrid model outputs agreed well with experimental results and the compatibility between MSK and FE models was assessed. The fingertip reaction force estimated by the hybrid model was $46.7 \pm 10.3 \mathrm{~N}$, lower than the experimental measurement by the force sensor $(61.1 \pm 12.1 \mathrm{~N})$. The hybrid model estimated a tendon force to external fingertip force ratio of $2.5 \pm 0.9$ and $2.4 \pm 1.2$ for FDP and FDS, respectively, and a ratio of proximal slip band to terminal extensor band tensions of $1.9 \pm 0.3$ for the extensor mechanism, as shown in Table 3. The joint reaction forces estimated by the hybrid model were higher than those of the MSK model but remained within one standard deviation. The sum of DIP, PIP and MCP joint reaction forces was $255.5 \pm 111.3 \mathrm{~N}$, $394.7 \pm 111.8 \mathrm{~N}$ and $585.9 \pm 119.8 \mathrm{~N}$, respectively. The results are summarized in Table 4.

\section{Joint mechanical stresses estimated by the hybrid model}

Joint contact pressure on cartilage surfaces and Von Mises stress distribution on bones of the index finger during a pinch grip task for one dataset of tendon forces are displayed in Figure 4. The highest stress was found on the surface of the metacarpal bone. High stress-intensity regions were visible at bone-pulley and bone-ligament interfaces because of the node coupling points (Figure 4). However, these highly localized stresses were due to numerical artefacts and considered not representative of the real bone condition. Finger joint contact areas were computed by summing all the facets bearing contact force and yielded $\quad 55.3 \pm 2.9 \mathrm{~mm}^{2}, \quad 79.4 \pm 2.2 \mathrm{~mm}^{2} \quad$ and
$105.0 \pm 3.5 \mathrm{~mm}^{2}$ for DIP, PIP and MCP joints, respectively. Mean contact pressure was calculated by averaging pressure values on the contact area at each joint (Figure 4). For DIP, PIP, and MCP joints, maximal contact pressure was $32.6 \pm 9.0 \mathrm{MPa}$, $34.0 \pm 8.4 \mathrm{MPa}$, and $37.2 \pm 7.5 \mathrm{MPa}$ and mean contact pressure was $6.9 \pm 2.7 \mathrm{MPa}, \quad 6.2 \pm 1.0 \mathrm{MPa}$, and $7.2 \pm 1.3 \mathrm{MPa}$, respectively, as shown in Table 5 .

\section{Sensitivity analysis}

Sensitivity analysis on cartilage showed that modifying the mechanical properties and thickness lead to significant joint contact pressure differences. Increasing the Young's modulus of $10 \%$ resulted in a variation of $9 \%$ on mean contact pressure on average. On sensitivity to tendon force, the results showed that the joint contact pressure decreased linearly with the tendon force intensity. Decreasing the tendon forces intensity of $20 \%$ resulted in a variation of $16 \%$ on mean contact pressure on average. Further details can be found in Supplementary Material B.

\section{Discussion}

We described here the development, first application and assessment of a hybrid model to estimate contact pressure in the three index finger joints during a static maximal strength pinch grip task. A FE environment has been developed to allow simulations of a multiarticular chain, stabilized by the equilibrium of external forces through the action of the ligaments and the tendon-pulley system, and driven by tendon forces estimated by a MSK model. This method combines two different numerical hand models to estimate joint mechanical stresses, notably mean and 


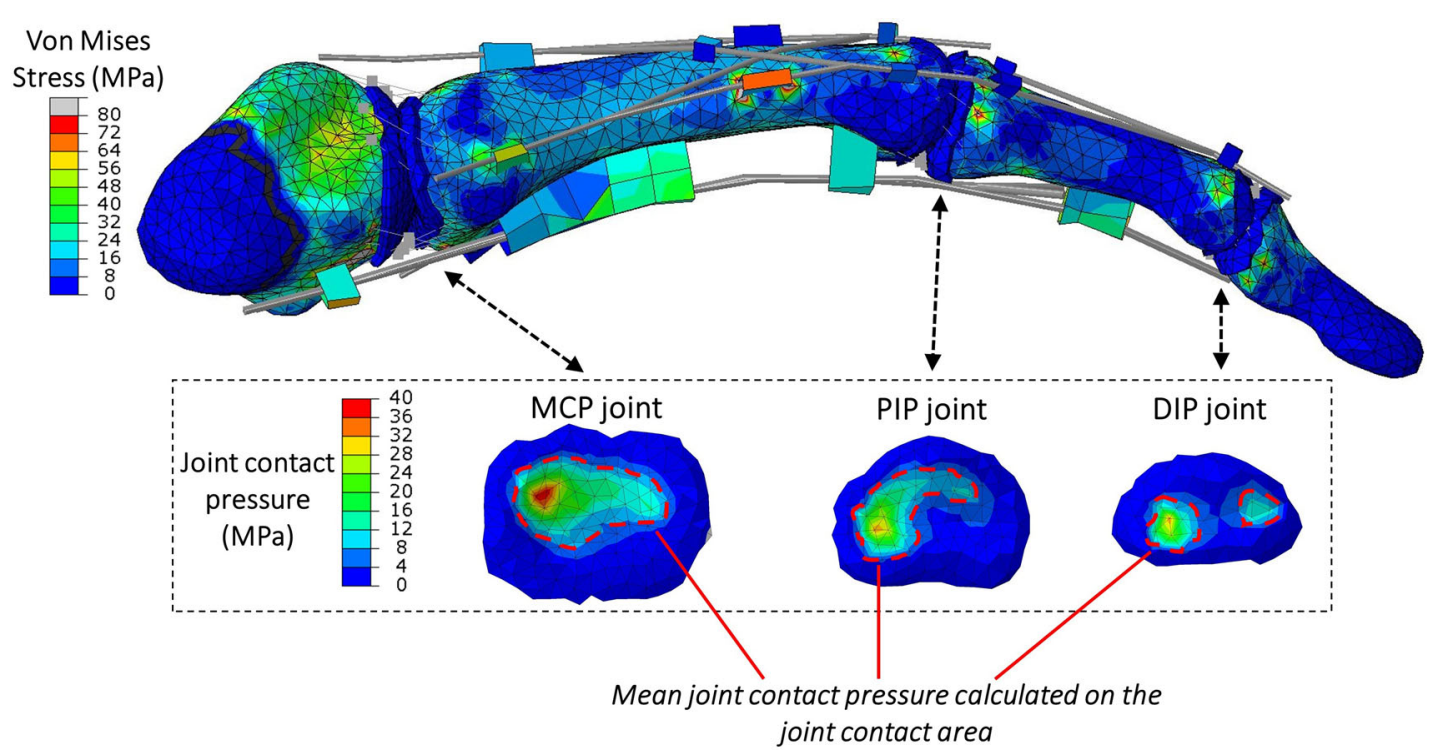

Figure 4. Von Mises stress distribution of the index finger and contact pressure distribution at distal interphalangeal (DIP), proximal interphalangeal (PIP) and metacarpophalangeal (MCP) joints during a static maximal strength pinch grip task applying one dataset of tendon forces.

Table 5 Cartilage contact pressures at distal interphalangeal (DIP), proximal interphalangeal (PIP) and metacarpophalangeal (MCP) joints and external fingertip force estimated by the hybrid model for each of the six subjects.

\begin{tabular}{|c|c|c|c|c|c|c|c|}
\hline & & \multicolumn{6}{|c|}{ Subject number } \\
\hline & & 1 & 2 & 3 & 4 & 5 & 6 \\
\hline \multirow{8}{*}{ Cartilage contact pressure (MPa) } & \multirow[b]{2}{*}{ DIP joint } & $\sigma_{\max }=19.3$ & $\sigma_{\max }=30.3$ & $\sigma_{\max }=29.2$ & $\sigma_{\max }=34.9$ & $\sigma_{\max }=34.7$ & $\sigma_{\max }=46.9$ \\
\hline & & $\sigma_{\text {mean }}=4.4$ & $\sigma_{\text {mean }}=5.7$ & $\sigma_{\text {mean }}=5.3$ & $\sigma_{\text {mean }}=7.5$ & $\sigma_{\text {mean }}=6.4$ & $\sigma_{\text {mean }}=12.0$ \\
\hline & \multirow{2}{*}{ PIP joint } & $\sigma_{\max }=25.5$ & $\sigma_{\max }=32.2$ & $\sigma_{\max }=30.7$ & $\sigma_{\max }=27.2$ & $\sigma_{\max }=46.8$ & $\sigma_{\max }=41.7$ \\
\hline & & $\sigma_{\text {mean }}=5.3$ & $\sigma_{\text {mean }}=5.8$ & $\sigma_{\text {mean }}=6.2$ & $\sigma_{\text {mean }}=5.2$ & $\sigma_{\text {mean }}=8.0$ & $\sigma_{\text {mean }}=6.7$ \\
\hline & \multirow{4}{*}{$M C P$ joint } & $\sigma_{\max }=32.9$ & $\sigma_{\max }=34.3$ & $\sigma_{\max }=40.7$ & $\sigma_{\max }=26.6$ & $\sigma_{\max }=48.1$ & $\sigma_{\max }=40.5$ \\
\hline & & $\sigma_{\text {mean }}=6.1$ & $\sigma_{\text {mean }}=6.5$ & $\sigma_{\text {mean }}=7.8$ & $\sigma_{\text {mean }}=5.8$ & $\sigma_{\text {mean }}=9.2$ & $\sigma_{\text {mean }}=7.7$ \\
\hline & & $F_{\exp }=42.5$ & $F_{\exp }=62.4$ & $F_{\exp }=65.2$ & $F_{\exp }=53.5$ & $\mathrm{~F}_{\exp }=78.4$ & $F_{\exp }=64.7$ \\
\hline & & $\mathrm{F}_{\mathrm{sim}}=36.3$ & $\mathrm{~F}_{\mathrm{sim}}=41.5$ & $\mathrm{~F}_{\mathrm{sim}}=44.1$ & $\mathrm{~F}_{\mathrm{sim}}=40.8$ & $\mathrm{~F}_{\mathrm{sim}}=64.4$ & $\mathrm{~F}_{\mathrm{sim}}=52.9$ \\
\hline
\end{tabular}

maximal joint contact pressures. To the best of our knowledge, this study is the first attempt to apply such multi-articular hybrid model to the hand joints. The obtained results confirmed that this innovative approach provides relevant information on hand mechanical loading during daily grip tasks which is promising for evaluating rehabilitation processes, simulating surgical procedures and understanding overuse injuries.

\section{Assessment of the hybrid model}

When evaluated through a combination of sensitivity analysis and comparison with experimental measurements, MSK results and literature data, the hybrid model was shown to provide a realistic estimation of hand loadings. First, the estimated fingertip reaction force was in good agreement with the experimental grip force, with only a $23 \%$ difference on average. This gap could be due to the use of a single bone geometry in the hybrid model, whereas the experimental gripping task involved six subjects, each with a different bone geometry. Secondly, there was good agreement in resultant joint reaction forces between the hybrid and the MSK models. Differences between the hybrid and the MSK model may be explained by the use of different assumptions in the two numerical approaches, such as non-deformable bodies in the MSK model versus deformable bones and cartilages with accurate geometries in the hybrid model. Lastly, joint contact areas predicted in the hybrid model showed similar values, with differences of less than $22 \%$ on average, to those of the MSK model and literature data (Moran et al. 1985). Despite these good agreement with in-vivo and in-vitro data, the full validation of the model is almost impossible as the direct measurement of joint contact pressure is ethically and technically difficult. Measurements devices are still too invasive and existing literature data are very limited. Available studies indeed provide only an in-vitro estimation of joint contact pressure at a low pinch grip force of $10 \mathrm{~N}$ (Moran et al. 1985) 
and of joint contact force at the MCP joint without considering physiological tendon co-contractions and joint contact pressure (Synek et al. 2019). Nevertheless, the good agreement between experimentally measured and the simulated fingertip forces, contact areas and tendon forces is encouraging. This suggests that the proposed approach based on a hybrid model is promising to determine internal biomechanical forces such as joint contact pressure.

The hybrid model proposes a new multi-articular tendon force transmission based on a tendon-pulley system, where flexor and extensor tendons slide in annular pulleys and sheaths, respectively. This represents an improvement over previous studies on finger joints (Harih 2019; Wei et al. 2020) and toe joints (Isvilanonda et al. 2012; Morales-Orcajo et al. 2015) which represented the tendon force transmission through wire connectors without considering either pulleys or the wrapping phenomena. Despite this achievement, the validation of tendon force transmission still represents a challenge due to the complexity of the geometric network and tendon bands. However, we found that the ratio of flexor tendon forces to fingertip force was consistent with in-vivo intraoperative measurements found in the literature (Schuind et al. 1992; Dennerlein et al. 1998; Kursa et al. 2005) (Table 3). Regarding the extensor mechanism, the ratio of proximal slip band to terminal extensor band tensions agreed with in-vitro results of (Valero-Cuevas et al. 2007) for the same ratio of input interosseous force (LU+ UI + RI) to extensor force (EDC + EDI). This comparison with experimental studies confirmed that the distribution of tendon forces through our index finger hybrid model is physiologically realistic without user driving nor parameter adjustment.

Cartilage modelling was a crucial step in the model development. It was represented as a monophasic time-independent hyperelastic material that could handle large deformations greater than 5\%. Although this did not account for either poroelastic behaviour or fluid-solid interactions such as osmotic swelling or mechanical exudation of interstitial fluid (Halloran et al. 2012), hyperelastic models are deemed adequate to represent articular cartilage under compressive loading (Brown et al. 2009). Cartilage thicknesses defined in the hybrid model were consistent with literature data (Robson et al. 1995; Möller et al. 2009). Sensitivity analysis on cartilage showed that its mechanical properties and thickness are discriminant parameters influencing results in a FE model studying joint mechanical behaviour, confirming a previous study (Dar and Aspden 2003). Further studies have to be conducted to accurately define those parameters as only one study provided such material properties at the hand joints (Dourthe et al. 2019).

\section{Joint contact pressures estimated by the hybrid model}

Calculation of mean contact pressures for the maximal voluntary contraction task performed by the six subjects showed significant inter-subject differences. This is due to different measured external forces resulting in a variability in the estimates of tendon forces and thus in joint contact pressure. Despite those variations, two groups of subjects could be identified. For subjects 4 and 6, mean contact pressures resulted in greater values for the DIP joint than for PIP and MCP joints while for the remaining four subjects, the MCP joint contact pressure was higher than in the PIP and DIP joints. Interestingly, the higher DIP loadings for the former group may show that these subjects are at greater risk of OA as several studies have shown that $\mathrm{OA}$ is more frequent in the DIP joint than in the proximal finger joints for the pinch grip position (Moran et al. 1985; Jensen et al. 1999; McQuillan et al. 2016). Although there is no consensus, it has indeed been suggested that cumulative excessive stresses acting on joints can lead to the occurrence and development of OA (Guilak 2011; Buckwalter et al. 2013). For these two subjects, PIP and MCP joints angles were lower than those of the other subjects resulting in different joint moment arms and thus in a different activation of tendon forces through the index finger. The FDP to FDS and FDP to LE tendon forces ratios were different with a muscular activation strategy acting more on the FDP tendon than on the FDS and LE ones. Overall tendon co-contraction could thus explain the high DIP joint contact pressure, but for both subjects, the sum of all tendon forces was equivalent to that of the other subjects (See Supplementary Material A). This shows that a biomechanical neuromuscular strategy leading to disadvantageous and compromising postures and thus to a different tendon force distribution could also be an OA risk factor, in addition to the specificity of the pinch grip position itself. Nevertheless, studies have shown that OA could develop in the MCP joint even during a maximal strength pinch grip task (Jensen et al. 1999). Therefore, findings of our study need to be further improved with a larger number of subjects.

Other information relative to the risk of OA could be obtained from the mean and maximal contact 
pressure values. Mean contact pressures obtained in the hybrid simulation (Table 5) do not suggest excessive or traumatic use of the cartilage. Indeed, this value can be considered as normal loadings needed for cartilage development and renewal, and to maintain functional integrity (Vanwanseele et al. 2002), thus keeping cartilage healthy (Parkkinen et al. 1992; Clements et al. 2001). However, peak contact pressures at DIP, PIP and MCP joints (higher than $15 \mathrm{MPa}$ ) corresponded to an excessive mechanical load which could cause chondrocyte death and extracellular matrix damage (Torzilli et al. 1999), thus leading to $\mathrm{OA}$ initiation. Nevertheless, it should be kept in mind that only two repetitions of the pinch grip task at extreme force levels were asked to the subjects in the experimental protocol. While a pinch grip strength of $10 \mathrm{~N}$ will suffice for $90 \%$ of daily living activities (Hunter et al. 1978), the measured and simulated pinch forces here were more than 5 times higher (around $60 \mathrm{~N}$ ). Thus, the studied task could be considered as a worst-case scenario. Further studies should therefore focus on submaximal forces and longitudinal studies of cartilage uses to provide more accurate information on the mechanical risk factors associated with the pinch grip technique. This could help in explaining the fact that OA has also been associated with less frequently used or even immobilized joints (Seedholm et al. 1979).

\section{Conclusion}

The hybrid method presented in this article combines two numerical approaches commonly used in computation biomechanics to estimate the local stress distribution in the three index finger joints using noninvasive in-vivo data. The agreement between experimental and simulated fingertip forces as well as tendon forces and joint contact areas suggest this new model allows for realistic simulations of the finger biomechanics. Further development of this hybrid method could allow simulating the whole hand and other daily life tasks such as the power grip and thus offer a better understanding of the mechanical determinants and consequences of joint diseases such as OA. A deeper understanding of the biomechanics of the hand related to joint disease occurrence provides the groundwork for improving surgical procedures, such as arthrodesis, through more efficient numerical models.

\section{Acknowledgment}

The authors would like to thank André Jacques for his help with the numerical simulations.

\section{Disclosure statement}

No benefits in any form have been or will be received from a commercial party related directly or indirectly to the subject of this manuscript.

\section{References}

An KN, Chao EY, Cooney WP, Linscheid RL. 1979. Normative model of human hand for biomechanical analysis. J Biomech. 12(10):775-788.

Anderson AE, Ellis BJ, Maas SA, Weiss JA. 2010. Effects of idealized joint geometry on finite element predictions of cartilage contact stresses in the hip. J Biomech. 43(7): 1351-1357.

Andriacchi TP, Koo S, Scanlan SF. 2009. Gait mechanics influence healthy cartilage morphology and osteoarthritis of the knee. J Bone Joint Surg Am. 91(Suppl 1):95-101.

Bardo A, Vigouroux L, Kivell TL, Pouydebat E. 2018. The impact of hand proportions on tool grip abilities in humans, great apes and fossil hominins: a biomechanical analysis using musculoskeletal simulation. J Hum Evol. 125:106-121.

Barry AJ, Murray WM, Kamper DG. 2018. Development of a dynamic index finger and thumb model to study impairment. J Biomech. 77:206-210.

Besier TF, Gold GE, Beaupré GS, Delp SL. 2005. A modeling framework to estimate patellofemoral joint cartilage stress in vivo. Med Sci Sports Exerc. 37(11):1924-1930.

Brown CP, Nguyen TC, Moody HR, Crawford RW, Oloyede A. 2009. Assessment of common hyperelastic constitutive equations for describing normal and osteoarthritic articular cartilage. Proc Inst Mech Eng $\mathrm{H}$. 223(6):643-652.

Buckwalter JA, Anderson DD, Brown TD, Tochigi Y, Martin JA. 2013. The roles of mechanical stresses in the pathogenesis of osteoarthritis: implications for treatment of joint injuries. Cartilage. 4(4):286-294.

Burkhart TA, Andrews DM, Dunning CE. 2013. Finite element modeling mesh quality, energy balance and validation methods: a review with recommendations associated with the modeling of bone tissue. J Biomech. 46(9): 1477-1488.

Butz KD, Merrell G, Nauman EA. 2012a. A biomechanical analysis of finger joint forces and stresses developed during common daily activities. Comput Methods Biomech Biomed Eng. 15(2):131-140.

Butz KD, Merrell G, Nauman EA. 2012b. A three-dimensional finite element analysis of finger joint stresses in the MCP joint while performing common tasks. Hand (N Y). 7(3):341-345.

Cheung J-M, Zhang M, Leung A-L, Fan Y-B. 2005. Threedimensional finite element analysis of the foot during standing-a material sensitivity study. J Biomech. 38(5): 1045-1054.

Choi H-H, Hwang S-M, Kang YH, Kim J, Kang BS. 2002. Comparison of implicit and explicit finite-element 
methods for the hydroforming process of an automobile lower arm. Int J Adv Manuf Technol. 20(6):407-413.

Clements KM, Bee ZC, Crossingham GV, Adams MA, Sharif M. 2001. How severe must repetitive loading be to kill chondrocytes in articular cartilage? Osteoarthr Cartil. 9(5):499-507.

Completo A, Nascimento A, Girão AF, Fonseca F. 2018. Biomechanical evaluation of pyrocarbon proximal interphalangeal joint arthroplasty: an in-vitro analysis. Clin Biomech (Bristol, Avon). 52:72-78.

Dar FH, Aspden RM. 2003. A finite element model of an idealized diarthrodial joint to investigate the effects of variation in the mechanical properties of the tissues. Proc Inst Mech Eng H. 217(5):341-348.

Dennerlein JT, Diao E, Mote CD, Rempel DM. 1998. Tensions of the flexor digitorum superficialis are higher than a current model predicts. J Biomech. 31(4):295-301.

D'Lima DD, Patil S, Steklov N, Slamin JE, Colwell CW. 2006. Tibial forces measured in vivo after total knee arthroplasty. J Arthroplasty. 21(2):255-262.

Dourthe B, Nickmanesh R, Wilson DR, D'Agostino P, Patwa AN, Grinstaff MW, Snyder BD, Vereecke E. 2019. Assessment of healthy trapeziometacarpal cartilage properties using indentation testing and contrast-enhanced computed tomography. Clin Biomech (Bristol, Avon)). 61:181-189.

Fowler NK, Nicol AC. 2000. Interphalangeal joint and tendon forces: normal model and biomechanical consequences of surgical reconstruction. J Biomech. 33(9): 1055-1062.

Garcia-Elias M, An K-N, Berglund LJ, Linscheid RL, Cooney WP, Chao E. 1991. Extensor mechanism of the fingers. II. Tensile properties of components. J Hand Surg. 16(6):1136-1140.

Gíslason MK, Stansfield B, Nash DH. 2010. Finite element model creation and stability considerations of complex biological articulation: the human wrist joint. Med Eng Phys. 32(5):523-531.

Goislard de Monsabert B, Rossi J, Berton E, Vigouroux L. 2012. Quantification of hand and forearm muscle forces during a maximal power grip task. Med Sci Sports Exerc. 44(10):1906-1916.

Goislard de Monsabert B, Vigouroux L, Bendahan D, Berton E. 2014. Quantification of finger joint loadings using musculoskeletal modelling clarifies mechanical risk factors of hand osteoarthritis. Med Eng Phys. 36(2): 177-184.

Guilak F. 2011. Biomechanical factors in osteoarthritis. Best Pract Res Clin Rheumatol. 25(6):815-823.

Halloran JP, Sibole S, van Donkelaar CC, van Turnhout MC, Oomens CWJ, Weiss JA, Guilak F, Erdemir A. 2012. Multiscale mechanics of articular cartilage: potentials and challenges of coupling musculoskeletal, joint, and microscale computational models. Ann Biomed Eng. 40(11):2456-2474.

Halonen KS, Dzialo CM, Mannisi M, Venäläinen MS, de Zee M, Andersen MS. 2017. Workflow assessing the effect of gait alterations on stresses in the medial tibial cartilage - combined musculoskeletal modelling and finite element analysis. Sci Rep. 7(1)17396.

Harih G. 2019. Development of a tendon driven finger joint model using finite element method. In: Cassenti DN, editor. Advances in Human Factors in Simulation and Modelling [Internet]. Vol. 780. Cham: Springer International Publishing; p. 463-471.

Hashizume $\mathrm{H}$, Akagi $\mathrm{T}$, Watanabe $\mathrm{H}$, Inoue $\mathrm{H}$, Ogura $\mathrm{T}$. 1994. Stress analysis of PIP joints using the three-dimensional finite element method. In: Schuind $\mathrm{F}$, An $\mathrm{KN}$, Cooney WP, Garcia-Elias M, editors. Advances in the Biomechanics of the Hand and Wrist [Internet]. Boston (MA): Springer US; p. 237-244.

Henak CR, Anderson AE, Weiss JA. 2013. Subject-specific analysis of joint contact mechanics: application to the study of osteoarthritis and surgical planning. J Biomech Eng. 135(2):021003.

Hunter J, Schneider L, Mackin E, Bell J. 1978. Rehabilitation of the hand. St Louis: Mosby.

Isvilanonda $\mathrm{V}$, Dengler $\mathrm{E}$, Iaquinto JM, Sangeorzan BJ, Ledoux WR. 2012. Finite element analysis of the foot: model validation and comparison between two common treatments of the clawed hallux deformity. Clin Biomech (Bristol, Avon). 27(8):837-844.

Jensen V, Bøggild H, Johansen JP. 1999. Occupational use of precision grip and forceful gripping, and arthrosis of finger joints: a literature review. Occup Med (Lond). 49(6):383-388.

Kursa K, Diao E, Lattanza L, Rempel D. 2005. In vivo forces generated by finger flexor muscles do not depend on the rate of fingertip loading during an isometric task. J Biomech. 38(11):2288-2293.

Lin GT, Amadio PC, An KN, Cooney WP. 1989. Functional anatomy of the human digital flexor pulley system. J Hand Surg. 14(6):949-956.

Maas SA, Erdemir A, Halloran JP, Weiss JA. 2016. A general framework for application of prestrain to computational models of biological materials. J Mech Behav Biomed Mater. 61:499-510.

McQuillan TJ, Kenney D, Crisco JJ, Weiss A-P, Ladd AL. 2016. Weaker functional pinch strength is associated with early thumb carpometacarpal osteoarthritis. Clin Orthop Relat Res. 474(2):557-561.

Minami A, An KN, Cooney WP, Linscheid RL, Chao EY. 1985. Ligament stability of the metacarpophalangeal joint: a biomechanical study. J Hand Surg. 10(2): 255-260.

Möller B, Bonel H, Rotzetter M, Villiger PM, Ziswiler H-R. 2009. Measuring finger joint cartilage by ultrasound as a promising alternative to conventional radiograph imaging. Arthritis Rheum. 61(4):435-441.

Morales-Orcajo E, Bayod J, Becerro-de-Bengoa-Vallejo R, Losa-Iglesias M, Doblare M. 2015. Influence of first proximal phalanx geometry on hallux valgus deformity: a finite element analysis. Med Biol Eng Comput. 53(7): 645-653.

Moran JM, Hemann JH, Greenwald AS. 1985. Finger joint contact areas and pressures. J Orthop Res. 3(1):49-55.

Napier JR. 1956. The prehensile movements of the human hand. J Bone Joint Surg Br. 38-B(4):902-913.

Parkkinen JJ, Lammi MJ, Helminen HJ, Tammi M. 1992. Local stimulation of proteoglycan synthesis in articular cartilage explants by dynamic compression in vitro. J Orthop Res. 10(5):610-620.

Rikli DA, Honigmann P, Babst R, Cristalli A, Morlock MM, Mittlmeier T. 2007. Intra-articular pressure 
measurement in the radioulnocarpal joint using a novel sensor: in vitro and in vivo results. J Hand Surg Am. 32(1):67-75.

Robson MD, Hodgson RJ, Herrod NJ, Tyler JA, Hall LD. 1995. A combined analysis and magnetic resonance imaging technique for computerised automatic measurement of cartilage thickness in the distal interphalangeal joint. Magn Reson Imaging. 13(5):709-718.

Schuind F, Garcia-Elias M, Cooney WP, An KN. 1992. Flexor tendon forces: in vivo measurements. J Hand Surg. 17(2):291-298.

Seedholm BB, Takeda T, Tsubuku M, Wright V. 1979. Mechanical factors and patellofemoral osteoarthrosis. Ann Rheum Dis. 38(4):307-316.

Synek A, Lu S-C, Vereecke EE, Nauwelaerts S, Kivell TL, Pahr DH. 2019. Musculoskeletal models of a human and bonobo finger: parameter identification and comparison to in vitro experiments. PeerJ. 7:e7470.

Synek A, Pahr DH. 2016. The effect of the extensor mechanism on maximum isometric fingertip forces: a numerical study on the index finger. J Biomech. 49(14): 3423-3429.

Torzilli PA, Grigiene R, Borrelli J, Helfet DL. 1999. Effect of impact load on articular cartilage: cell metabolism and viability, and matrix water content. J Biomech Eng. 121(5):433-441.
Valero-Cuevas FJ, Yi J-W, Brown D, McNamara RV, Paul C, Lipson H. 2007. The tendon network of the fingers performs anatomical computation at a macroscopic scale. IEEE Trans Biomed Eng. 54(6 Pt 2):1161-1166.

Vanwanseele B, Eckstein F, Knecht H, Stüssi E, Spaepen A. 2002. Knee cartilage of spinal cord-injured patients displays progressive thinning in the absence of normal joint loading and movement. Arthritis Rheum. 46(8): 2073-2078.

Vergara M, Sancho-Bru JL, Gracia-Ibáñez V, PérezGonzález A. 2014. An introductory study of common grasps used by adults during performance of activities of daily living. J Hand Ther. 27(3):225-233; quiz 234.

Vigouroux L, Quaine F, Labarre-Vila A, Moutet F. 2006. Estimation of finger muscle tendon tensions and pulley forces during specific sport-climbing grip techniques. J Biomech. 39(14):2583-2592.

Wei Y, Zou Z, Wei G, Ren L, Qian Z. 2020. Subject-specific finite element modelling of the human hand complex: muscle-driven simulations and experimental validation. Ann Biomed Eng. 48(4):1181-1195.

Wright V, Dowson D. 1976. Lubrication and cartilage. J Anat. 121(Pt 1):107-118.

Zancolli E. 1979. Structural and dynamic bases of hand surgery. 2nd ed. Philadelphia (PA): Lippincott. 